\title{
Exploring the effect of Java mobile dictionaries on Iranian EFL students' vocabulary learning
}

\author{
Mostafa, Zare \\ University of Isfahan, Iran (Mostafa.zare314@gmail.com) \\ Zahra, Amirian \\ University of Isfahan, Iran (Amirian_z@yahoo.com)
}

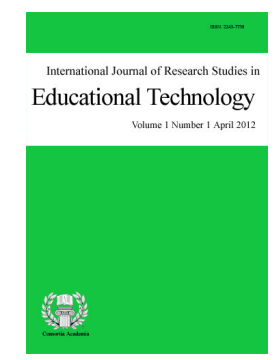

ISSN: $2243-7738$ Online ISSN: 2243-7746

\section{Abstract}

In recent years, we have witnessed the concomitant rise of Mobile Assisted Language Learning (MALL) in educational and academic settings. This study aimed to explore the effect of an aspect of MALL i.e. Java mobile dictionaries on EFL students' vocabulary learning. To this end, the researchers divided forty intermediate Iranian EFL learners into experimental and control group. Both groups, initially, took the pretest designed based on the vocabulary in the course book, Touchstone 3. While the experimental group received three java mobile dictionaries and installed them on their mobile phones, the control group attended conventional classes without any additional tool. Experimental group took the advantage of their mobile dictionaries throughout the course looking up the meaning of unknown words. After the treatment both groups firstly filled out a questionnaire which would elicit the learners' attitude toward java mobile dictionaries. Then, they took the posttest. Results of t-tests run revealed that the experimental group students significantly outperformed their control group counterparts in EFL vocabulary learning. Moreover, the students exhibited their pronounced tendency to use Java mobile dictionaries in vocabulary learning.

Keywords: Mobile-learning; Mobile assisted language learning; Java mobile dictionaries; Vocabulary learning; Learners' attitudes 


\section{Exploring the effect of Java mobile dictionaries on Iranian EFL students' vocabulary learning}

\section{Introduction}

Having a short flashback to one or two decades ago reveals that the most conspicuous changes one may easily notice lie in substantial information and communication advances. One of the quintessential instruments representing these advances is undoubtedly mobile phone. This technology has been currently serving the human's welfare even in the remote regions of the world. According to Tai and Ting (2011), mobile devices have become commonplace tools in a wide array of settings that may include teaching and learning alongside work and leisure, both in formal and informal settings. One of the basic advantages of mobile phones, which has attracted a host of researchers, is the utilization of mobile phones to provide a more accurate, active and effective learning. All tendencies and endeavors to positively take advantage of mobile phones' potentials in learning have been termed "mobile learning" (m-learning). The ready-in-hand access of mobile devices which could function as a personal 'learning hub' (Looi et al., 2010 as cited in Wong, Chin, Tan, Liu, \& Gong, 2010), has initiated a new evolutionary wave of technology-enhanced learning (Chan et al., 2006).

An area in which m-learning has proven to be strongly effective is foreign language learning. Derakhshan and Khodabakhshzadeh (2011) contend that as foreign language students usually have limited opportunities to speak and hear the target language, it seems necessary to draw on other kinds of practice and exposure. A possible solution to compensate for these educational constraints can be to expose students to virtual language-related environments. According to Canny (2010, as cited in Miangah \& Nezarat, 2012), cell phones offer an ideal platform for learning since they are ubiquitous, affordable, compact and wireless. Mobile applications which have been mainly used in language learning include short message service (SMS), recording voice services and email services. However, some applications and their role in language learning have been neglected. One such type of applications is java applications.

One of the fastest growing sections of technological development in recent years has been mobile devices. Therefore, as in other fields, practitioners in the field of second or foreign language learning have attempted to implement the use of mobile devices, especially mobile phones, in language teaching and learning. As noted above, the usage of Java applications in mobile phones and its probable impact on foreign language learning has been overlooked in the literature. Java is the most object-oriented programming language. Java applications run on Windows, Mac OS X, Linux, Solaris and many other operating systems. Most of the operating systems developed for mobile phones, such as Android, Windows mobile, Bada and Symbian, also run Java applications. Among the Java applications, use of mobile dictionaries have increasingly grown recently and favored by mobile phone users all over the world. Ubiquity of Java applications as well as the importance of vocabulary leaning as a fundamental part of any language learning program were the main impetus for this study exploring whether or not the use of Java mobile dictionaries has any effect on students' EFL vocabulary learning. Moreover, the learners' attitude toward the use of these applications has been sought.

\subsection{Significance of the study}

In spite of the fact that the use of mobile dictionaries has remarkably been on the rise during the last few years, the number of studies which have systematically investigated their role as a tool for promoting the efficiency of learning and teaching languages is few. The present study gains significance as it can shed light on the effectiveness of mobile assisted language learning (MALL), in general, and Java mobile dictionaries, in particular on speeding up foreign language vocabulary learning. The results of this study prove useful to syllabus designers in developing programs which take the advantage of mobile phones in pedagogic contexts. The findings of this study also help EFL teachers to facilitate the process of language teaching and learning through 
Exploring the effect of Java mobile dictionaries on Iranian EFL students' vocabulary learning supplementing previous paper dictionaries with newer, easier-to-use mobile dictionaries in language classrooms

\section{Literature review}

\subsection{M-Learning}

Among all modern communication devices, mobile phones are the most powerful communication media since they can act as a learning device (Miangah \& Nezarat, 2012). Their personal, flexible and multifunctional nature gives mobile users the pleasure of getting information through different channels in different locations and times. When studying the growing literature on m-learning, one confronts with different definitions for m-learning (Ghorbandordinejad, Aghasafi, Farjadnasab, \& Hardani, 2010). In spite of the fact that m-learning is related to e-learning and distance learning, it is distinguished from them concerning its focus on learning across contexts and learning with mobile devices. The m-learning term covers learning with portable technologies including but not limited to handheld computers, MP3 players, notebooks and mobile phones.

Mobility of the learners interacting with portable technologies is highly emphasized in m-learning. As Alley (2009), Kukulska-Hulme and Traxler (2005) and Keegan (2002) aptly note, the portable and personal nature of these devices actualizes the slogan of m-learning that is "anywhere, anytime learning". Some definitions have been provided for m-learning. For instance, O’ Malley, Vavoula, Glew, Taylor, Sharples, and Lefrere (2003) state that "Any sort of learning that happens when the learner is not at a fixed, predetermined location, or learning that happens when the learner takes advantage of the learning opportunities offered by mobile technologies". Emphasizing the role of portability, Traxler (2009) defines m-learning as "any educational provision where the sole or dominant technologies are handheld or palmtop devices". Griffin (2010), regarding m-learning as a supplement to formal learning argues that "Mobile learning is a refresher of things students learn in a more extended formal training event".

Klopfer, Squire, and Jenkins (2002) mention the following properties of mobile phones as basic contributors to their enhanced popularity: a) portability: such devices can be taken to different places due to small size and weight, b) social interactivity: exchanging data and collaboration with other learners is possible through mobile devices, c) context sensitivity: the data on the mobile devices can be gathered and responded uniquely to the current location and time, d) connectivity: mobile devices can be connected to other devices, data collection devices, or a common network by creating a shared network, e) individuality: activities platform can be customized for individual learner.

Over the past two decades there appears to be a paradigmatic shift away from education and training to learning; from teacher-centered to student-centered education; from rote learning to learning as reflection; and from face-to-face to distance and e-learning (Jarvia, Holford, \& Griffin, 2003, as cited in Motallebzadeh, Behafarin, \& Daliry Rad, 2011). One of the highly important subsets of e-learning which has had and continues to have revolutionary impacts on the teaching and learning process is m-learning. As access to wireless networks expands and ownership of devices that can communicate with such networks increases, the use of mobile devices to support language learning becomes ever more common (Kukulska-Hulme \& Shield, 2008). Cruz-Flores and Lopez-Morteo (2008) argue that due to its deep penetration and its ubiquity, the cell phone seems to be the ideal "anytime, anyplace" educational technology.

\subsection{Mobile assisted language learning(MALL)}

MALL can be simply defined as the application of m-learning in foreign/second language learning. A wide range of devices have been used in MALL-based classes. Zhao (2005) stated that "other technologies that hold capacity for language learning include PDA, multimedia cellular phones, MP3 players, DVD players and digital dictionaries" (p.447). Of aforementioned devices, a combination of dictionaries and mobile phones creates a potential tool for learning and teaching second or foreign language. 
Mostafa, Z. \& Zahra, A.

Meanwhile, a crucial point regarding the use of mobile phones' applications in language learning is the technological infrastructure of a country. Thornton and Houser (2005), for example, asked 333 Japanese college students to rank the ten mostly used features of their mobile phones. Following sending and receiving e-mail which was, not surprisingly, ranked as the most frequent feature of cell phones used by Japanese students, voice call, web, photo, calendar, game, dictionary, 'to do' lists and video recording were the most frequently used features of mobile phones. This is mainly due to the convenient cost and speed of Internet in Japan. This may not be the case in developing countries like Iran. Owing to its instability and high cost, Internet connection via mobile phones in Iran has not been warmly welcomed by users. This is why mobile users prefer to have small java programs with offline databases which are inexpensive and easy to use without the need to Internet connection, e.g. java mobile dictionaries.

\subsection{Strategies for language and vocabulary learning}

Vocabulary plays an undeniably crucial role in learning a language. In fact, words are the building blocks of a language. Wilkins (1972) points out that "without grammar very little can be conveyed, without vocabulary nothing can be conveyed" (p. 111). All language practitioners have reached a high level of consensus regarding the importance of vocabulary. A good command of vocabulary facilitates the process of inferring meaning from sentences. On the other hand, Lin (2002) and Segler, Pain, and Sorace (2002) argue that a poor vocabulary frequently leads to misunderstanding the content or poor comprehension when reading articles.

EFL learners often adopt various strategies to learn the words. Vocabulary teaching and learning can be personalized according to the learners' different learning needs, goals and styles. Additionally, language learning strategies (LLSs) are important to language learning and a host of studies have confirmed that training students to use LLSs can help them become better language learners (Canale \& Swain, 1980; Oxford, 1990; Segler et al., 2002). Oxford (1990) defines LLSs as "specific actions taken by the learner to make learning easier, faster, more enjoyable, more self-directed, and more effective and more transferable to new situations" (p. 8). She also proposes a list of twelve key features involving LLSs. She believes that LLSs:

1. Contribute to the main goal, communicative competence.

2. Allow learners to become more self-directed.

3. Expand the role of teachers.

4. Are problem-oriented.

5. Are specific actions taken by the learner.

6. Involve many aspects of the learner, not just the cognitive.

7. Support learning both directly and indirectly.

8. Are not always observable.

9. Are often conscious.

10. Can be taught.

11. Are flexible.

12. Are influenced by a variety of factors.

Concerning vocabulary learning strategies (VLSs), Kim and Gilman (2008) note that vocabulary learning is often used with strategies such as word lists or paired associations in which new words are presented with their translations. Many traditional methods of learning English vocabulary such as learning new words through 
teachers' explicit explanation and reciting word lists are still widely used in many parts of the world. In a large-scale survey on VLSs, Schmitt (1997) investigated 600 Japanese learners from four different age levels. He found that $85 \%$ of the sample gave a positive response to the use of bilingual dictionaries to discover word meanings. The other most-used strategies were verbal repetition and written repetition. Schmitt, in his attempt to propose as thorough a list of VLSs as possible and classify them based on the current descriptive systems, initially resorted to Oxford's (1990) classification of LLSs. However, since Oxford's classification dealt with LLS in general, Schmitt added a new category for those strategies learners employ when discovering a new word's meaning without consulting other people, namely determination strategies (Lai, 2005). Schmitt finally came up with the following classification.

\section{Table 1}

Taxonomy of VLSS

\begin{tabular}{|c|c|c|}
\hline \multirow{6}{*}{$\begin{array}{l}\text { Vocabulary } \\
\text { Learning } \\
\text { Strategies } \\
\text { (VLS) }\end{array}$} & \multirow{2}{*}{$\begin{array}{l}\text { Discovery } \\
\text { Strategies }\end{array}$} & Determination strategies \\
\hline & & Social strategies \\
\hline & \multirow{4}{*}{$\begin{array}{l}\text { Consolidation } \\
\text { Strategies }\end{array}$} & Social strategies \\
\hline & & Memory strategies \\
\hline & & Cognitive strategies \\
\hline & & Metacognitive strategies \\
\hline
\end{tabular}

(Schmitt, 1997)

Discovery strategies include several determination strategies and social strategies as well. A learner may discover a new word's meaning through guessing from context, guessing from an L1 cognate, using reference materials (dictionaries) or asking someone else(e.g., teacher or classmates). For the present research purposes, we concentrate on mobile/electronic dictionary use as a VLS and its impact on second or foreign language vocabulary learning. As it is well witnessed in second or foreign language teaching and learning environments, dictionaries are among the first strategies employed by learners in vocabulary learning. With the rapid technological advancement over the past two decades, learners mostly tend to abandon their thick, difficult-to-use and heavy paper dictionaries and to search willingly for electronic versions of those dictionaries. There is a wealth of such electronic dictionaries being installed on PCs, laptops, tablets and smart phones. Electronic dictionaries have gone a step forward and emerged as Java mobile dictionaries which are supported by nearly all mobile phones.

\subsection{Previous studies}

In line with the burgeoning area of MALL, an extensive body of research studying the role of different aspects of mobile phones on language learning and the attitudes toward MALL has been conducted over the last few years. Thornton and Houser (2005), for instance, investigated email service of mobile phones in Japan. They sent 100-word English vocabulary lessons at timed intervals to the mobile phones of 441 Japanese university students. Compared with students who were studying the same materials on paper or web, they found that students receiving mobile emails learned significantly better. Moreover, seventy one percent of participants preferred receiving these lessons on mobile phones rather than PCs. Ninety three percent of them also rated mobile emails as a valuable teaching method which truly indicates the positive attitude of learners toward the application of MALL.

Investigating the use of mobile phones' built-in camera, Wong and Looi (2010) conducted a study with the aim of teaching English prepositions and Chinese idioms. To this end, the primary school students used the mobile devices assigned to them on a one-to-one basis to take photos in real life context so as to construct sentences with the newly acquired prepositions or idioms. The learners were, then, voraciously engaged in classroom or online discussion of their semantic construction. Furthermore, another aspect of mobile phones i.e. games, was investigated by Fotouhi-Ghazvini, Earnshaw, Robinson and Excell (2009). They devised a game 
package called "the MOBO city" in which there was a story, simplifying and exaggerating real life. As they claim elements of control, feedback and sense of danger were incorporated in the game. By producing an engaging learning experience, vocabularies were learned incidentally.

Short Message Service (SMS), as an educational tool for foreign language learning, has also been widely explored. Supporting SMS, Clark, Keing, Lam, and Mc Naught (2008) contend that despite the technology involved in the tasks (SMS) being relatively simple, we would like to suggest that simple strategies can also lead to considerable teaching and learning benefits. Besides, Motallebzadeh et al. (2011), studying the effect of SMS on the retention of collocations among Iranian students, reported better performance of SMS group versus conventional paper group students. Similar results were also achieved by Motallebzadeh and Ganjali (2011), Derakhshan and Khodabakhshzadeh (2011) and Khazaei and VahidDastjerdi (2011) delving into the effect of SMS on learning numerous sub skills of language.

In another branch of literature, Ghorbandordinejad et al. (2010) and Baleghizadeh and Oladrostam (2010) looked into the effect of recording devices in English classrooms and its influence on the grammatical accuracy of EFL students, respectively. In the first study students in both experimental and control groups received the same instruction in the same class. While control group were supposed to use traditional paper and pencil note taking, experimental group were allowed to record the voice of the class for subsequent uses. Computations revealed a marked difference in favor of experimental group. In the same vein, in Baleghizadeh and Oladrostam's study, participants in both groups were provided with an opportunity to review and recycle six grammatical forms. During class discussions designed in such a way as to elicit the given grammatical items, the participants in the experimental group analyzed their spoken mistakes and commented on them in the subsequent session. The control group participants, on the contrary, received no extra treatment. The results reflect that participants in MALL group outperformed control group participants on multiple choice grammar tests.

As the literature clearly depicts, despite the numerous aspects of mobile phones which have been studied as an aid for language learning, there are still steps to take probing areas which have not received as much attention as they deserve. One of such areas is the Java mobile dictionaries. Thus the present study is an attempt to find acceptable answers to the following research questions.

1. Do Java mobile dictionaries have any effect on foreign language vocabulary learning?

2. What is the learners' attitude toward the use of Java mobile dictionaries for foreign language?

\section{Method}

\subsection{Participants}

Forty intermediate EFL students from a private language institute in Iran were randomly selected to participate in this study. The sample was comprised of 28 female and 12 male students. Their age ranged from 18 to 25. Students had at least 6 years of experience in learning English during junior and senior high school periods. The homogeneity of the students was guaranteed as they had taken the placement test administrated by the institute. They were randomly assigned to two groups, experimental (A) and control (B) group (20 students in each), by the institute staff. Sources such as textbook, monolingual and bilingual paper dictionaries, workbook, and supplementary handouts were equally provided to both groups. The only difference between the groups was the provision of mobile dictionaries to the experimental group. Students in experimental group were asked to use these dictionaries in their daily in-class language learning activities.

\subsection{Instruments}

The instruments used in this study are as follows: 
A. Three java mobile dictionaries: the first one was the 2005 version of Cambridge Advanced Learners' Dictionary developed by Cambridge University Press. The next dictionary utilized in this research was the 2009 version of Concise Oxford Thesaurus Dictionary. The third dictionary was the version 2.0 Persian Mobile Dictionary (PMD) which is bilingual (English to Persian). Oxford advanced learners' dictionary acted as an original and monolingual source for looking up the meaning of words. To boost the students' vocabulary domain and to take into consideration the role of synonyms as a beneficial way to learn and recall the meaning of words, the Concise Thesaurus Dictionary was used. On the other hand, for those words which students could not get their exact meanings through monolingual dictionaries, PMD was presented.

B. An attitude questionnaire was given to students through which they were asked to write a paragraph stating their ideas about the following questions:

1. Do you like using java mobile dictionaries?

2. Do you have any experience using and working with these dictionaries?

3. Do you prefer using these dictionaries to paper dictionaries?

4. Do you have any suggestions regarding how to use these dictionaries more efficiently as a VLS in language classes?

The questionnaire was piloted with a group of 15 students who were at the same level of proficiency and at the same institute that the target participants were. To assure the understandability of the questionnaire, the students received and filled out the questionnaire in their native language i.e. Persian. The questionnaire was administrated right before the posttest.

C. Pre/Posttest: to gauge the efficacy of mobile dictionaries, a test which was developed and used by the institute as the final exam of the course was utilized. The original test measured all language skills of the students. However, just its vocabulary section was chosen as pre/posttest to achieve the present research goals. In addition, this test was piloted with a group of 15 students who had similar characteristics as target participants. The test was composed of 15 multiple-choice items covering the vocabulary in Touchstone book by McCarthy, McCarthy and Sandiford (2005) (this book was used to teach the intermediate level students at the institute). The reliability of the test measured through KR-21 method was found to be 0.82 which is acceptable. The item facility and item discrimination indexes were 0.48 and 0.52 respectively, which are convenient values. The scoring procedure employed was to assign a score to each correct answer. Therefore, the maximum possible score would be 15 .

\subsection{Procedure}

In order to accomplish its goals, this study used two groups each consisting of 20 participants. In addition to common materials (textbook, paper dictionaries and workbook) used by both groups dealing with daily vocabulary learning tasks, the experimental group students received three mobile dictionaries and were asked to use their mobile dictionaries in their language learning activities in the classroom. The same teacher taught the two groups. After having administrated the pretest to both groups, the next stage of the study started. At the treatment phase which took forty five days (three sessions a week), the teacher initially gave some instructions to experimental group students on how to use mobile dictionaries properly. Providing students with special opportunities, the teacher encouraged them to use their mobile dictionaries for checking spelling, pronunciation, meaning and example sentences. For instance, in reading section of the course, the students were asked to read the passage once and look up the meaning of unknown words through their monolingual and bilingual mobile dictionaries and then, referring to the concise thesaurus dictionary, write down synonyms and antonyms of new words.

Similarly, before commencing the listening, students were given enough time to check the pronunciation 
Mostafa, Z. \& Zahra, A.

and meaning of the words that they were going to hear. The procedure for applying mobile dictionaries in speaking and writing section also consisted of a pre-speaking and pre-writing session in which, taking the advantage of sample sentences in mobile dictionaries, the students had the chance to prepare what they wanted to express or write so as to produce well-formed sentences.

All these procedures were also conducted in the control group class with the only difference being the absence of mobile dictionaries inside the classroom. Moreover, we made sure that the control group learners did not have access to their mobile phones during the treatment phase inside the classroom as they were asked to hand their mobile phones in to the institution's staff as part of the regulations specific to the control group but not applicable to the experimental group. After having finished the treatment, first the questionnaire and then the posttest were administered to both groups. It is worth noting that the order of questions was changed in the posttest which was the same as the pretest.

\section{Results}

Having administrated the pretest, presenting treatment and giving posttest, we used SPSS 18 to conduct statistical analysis of students' performance. Two independent sample t-tests were run to compare the difference between the two groups.

\subsection{Results of the pretest}

In order to assess the level of students' vocabulary knowledge at the outset of the study, an independent sample t-test was run for both groups' performance on pretest.

Table 2

Descriptive Statistics for the Pretest

\begin{tabular}{lccccccc}
\hline \multicolumn{1}{c}{ Groups } & $\mathrm{N}$ & Mean & SD & Max Score & Min Score & $\mathrm{t}$ & $\mathrm{df}$ \\
\hline Experimental & 20 & 6.1 & 2.3 & 7 & 0 & $0.78^{*}$ & 38 \\
Control & 20 & 5.7 & 2.8 & 5 & 0 & & \\
\hline
\end{tabular}

Note. $* p<0.05$

As the results of Table 2 show, there was no statistically significant difference between the experimental group (Mean: 6.1, SD: 2.3) and the control group (Mean: 5.7, SD: 2.8). This point denotes that students were roughly at the same level of vocabulary knowledge at the outset of the study.

\subsection{Results of the posttest}

To find an acceptable answer to the first research question, another independent sample t-test was conducted. Table 3 below illustrates the descriptive statistics for posttest.

\section{Table 3}

Descriptive Statistics for the Posttest

\begin{tabular}{lccccccc}
\hline \multicolumn{1}{c}{ Groups } & $\mathrm{N}$ & Mean & $\mathrm{SD}$ & Max Score & Min Score & $\mathrm{t}$ & $\mathrm{df}$ \\
\hline Experimental & 20 & 12.3 & 2.02 & 15 & 9 & $3.29 *$ & 38 \\
Control & 20 & 9.2 & 3.04 & 15 & 5 & & \\
\hline
\end{tabular}

Note. ${ }^{*} p<0.05$

As Table 3 reveals, participants in the experimental (java mobile dictionaries) group (M: 12.3, SD: 2.02) significantly outperformed those in the control group (M: 9.2, SD: 3.04) concerning foreign language vocabulary learning. 


\subsection{Results of the questionnaire}

As it was noted before, the questionnaire was designed to shed light on four points:

1. Do the students like using java mobile dictionaries?

2. Do the students have any experience using and working with these dictionaries?

3. Do the students prefer using these dictionaries to paper dictionaries?

4. Do the students have any suggestions regarding how to use these dictionaries as a VLS more in language classes?

To answer the second research question, Table 4, 5 and 6 indicate that the students' attitudes toward the use of java mobile dictionaries as an EFL vocabulary learning tool.

\section{Table 4}

Learners' Answers to Question 1

\begin{tabular}{llcc}
\hline Items & Like & Dislike & Unanswered \\
\hline Experimental group & $85 \%$ & $15 \%$ & $0 \%$ \\
\hline Control group & $60 \%$ & $35 \%$ & $5 \%$ \\
\hline
\end{tabular}

Table 5

Learners' Answers to Question 2

\begin{tabular}{lccc}
\hline Items & Yes & No & Unanswered \\
\hline Experimental group & $10 \%$ & $80 \%$ & $10 \%$ \\
\hline Control group & $5 \%$ & $90 \%$ & $5 \%$ \\
\hline
\end{tabular}

Table 6

Learners' Answers to Question 3

\begin{tabular}{lccc}
\hline Items & Yes & No & Unanswered \\
\hline Experimental group & $85 \%$ & $10 \%$ & $5 \%$ \\
\hline Control group & $70 \%$ & $25 \%$ & $5 \%$ \\
\hline
\end{tabular}

As it is presented in table 4, students in both groups have exhibited their propensity for use of mobile dictionaries (Experimental: \%85, Control: \%60). Moreover, few of the participants in each group have had the experience of working with mobile dictionaries (Experimental: \%10, Control: \%5). Answers to the third question signify the students' inclination to use mobile/ electronic dictionaries more than the paper ones. The results of the fourth questions are debated in detail in discussion section.

\section{Discussion}

The present study was an attempt to examine the efficacy of using java mobile dictionaries in assisting foreign language students' vocabulary learning. As the findings of this experimental study demonstrate, Java applications can facilitate foreign language vocabulary learning. The results of the present study are in congruence with previous studies (Thornton \& Houser, 2005; Clark, et al., 2008; Fotouhi-Ghazvinchi et al., 2009; Motalebzadeh et al., 2011; Khazaei \& Vahid Dastjerdi, 2011) reporting that the use of mobile phones' features has had a positive effect on students' language learning. The findings of this study are also at odds with those of Salaberry (2001) who claims that mobile phones are not effective tools for learning.

Replying to the first research question, the results obtained in this study evince the remarkable influence of these dictionaries on the learners' vocabulary learning. A difference of approximately three points in the average score as well as a difference of four points in the minimum score confirms that the use of mobile dictionaries has 
reinforced the vocabulary domain of the experimental group. Therefore, in line with the points suggested at the literature section, this study acknowledges the pedagogical merits of MALL and justifies its widening scope in regard to what Klopfer et al. (2002) named as typical features of mobile phones like portability, social interactivity and connectivity.

Regarding the second research question, some more points can be concluded from the results. Looking over the questionnaire results, what one may find more eye-catching is the noteworthy tendency of students to the use of mobile dictionaries. Such auspicious viewpoints of students put the onerous burden of incorporating MALL-based technologies into the pedagogical programs on the shoulders of syllabus designers and language teachers as practitioners of these programs in classes. Based on the students' comments answering the first question of the questionnaire that was "Do the students like using java mobile dictionaries?" their dislikes might emanate from two sources. They either did not receive enough instructions on how to use mobile dictionaries or did not install appropriate kinds of mobile dictionaries. Mona, for instance, wrote "No, because I once used one of them but it did not cover all the words." Aria, similarly, wrote "No, it is difficult for me to work with mobile dictionaries". These statements are calls for a plan embracing sufficient instructions regarding the use of these applications and taking the advantage of updated and practical applications to pave the way for a more efficient language teaching and learning.

Answers to the second question that was whether the students had any experience using and working with these dictionaries revealed that the majority of learners did not have the opportunity to use mobile dictionaries for learning purposes. Results of third question that is "Do the students prefer using these dictionaries to paper dictionaries?" imply that it is the time for an inclusive shift from paper dictionaries to electronic dictionaries. Supporting this statement, Amirian and Heshmatifar (2013) argue that "the use of electronic dictionaries proved to be a powerful tool for improving students 'achievement in vocabulary learning and retention" (p.41). From now on, thus, we may see electronic dictionaries more frequently in VLSs classifications instead of generic term of dictionary use.

The students' answers to the third and fourth question are discussed jointly. Most of the students ignored the fourth question that was "Do the students have any suggestions regarding how to use these dictionaries as a VLS more in language classes". Although their answers reflected their enthusiasm for more frequent use of MALL activities in the classroom, nearly all of them failed to offer a direct and feasible suggestion concerning the implementation of these applications in language classes. Yet, some key points were made in their answers. One important point conceded in the students' comments on the question four is their satisfaction with the sense of autonomy derived from self-discovery of the words' meanings. This autonomy frees students from psychological pressure of recourse to others for the meaning of unknown words. Accordingly, Schmitt's claim (1997) that reference materials (e.g. dictionaries) are among determination strategies where the learners discover the meaning of word on their own is verified.

Another point raised in students' answers was their reasons for the preference of mobile dictionaries to paper ones. These reasons can be categorized under three headings: a) portability and accessibility; this is the first property that Klopfer et al., (2002) considered as contributing to the popularity of mobile phones. b) encountering considerable difficulties vis-à-vis the use of paper dictionaries (bulky, weighty and time consuming to use); While most of the students favored the use of mobile dictionaries, ten percent of the students in experimental group and twenty five percent of the control group students were willing to use paper dictionaries. The latter group believed in the view that the paper dictionaries were more reliable, easier to use and more comprehensive than mobile dictionaries. Omid, for example, in defense of paper dictionaries, said "words are usually incompletely defined in mobile dictionaries" and c) saving time and energy. This reason was stated by many learners. One of the learners wrote "While for looking up the meaning of a two-letter word I should browse many pages in a paper dictionary, I checked it so quickly on my mobile dictionary". 


\section{Conclusion}

This paper was generally an attempt to assess the effectiveness of using mobile phones for promoting EFL students' vocabulary learning. It can be concluded that the use of mobile dictionaries has significantly affected the students' performance in experimental group. As the findings of this study demonstrate, java applications of mobile phones could be widely used as a pedagogical tool for facilitating the foreign language vocabulary learning. Thus, these findings highlight the importance of MALL and its potentials as an attractive path through which success of teaching and learning process can be enhanced. Besides, students have shown that they desire to use mobile applications for language learning. Their positive attitudes toward MALL indicate that more technology-based tasks and activities will definitely contribute to better language learning.

This study bears some implications for syllabus designers to incorporate some technologic and mobile-based activities into the pedagogical language programs besides previous learning programs in which teacher, learner and blackboard were the only elements needed for a typical language classroom. Another implication of the study is for the teachers who mostly regard devices like MP3 players, tablets and mobile phones as innate distracters. The number of teachers thinking of portable electronic devices as obstacles to efficient language learning and teaching is not few. Notwithstanding such incorrect perceptions, the burgeoning area of MALL is progressively proving itself as a valuable pedagogical instrument all over the world.

\subsection{Limitations of the study}

Although the research was carefully prepared, there were unavoidable limitations. First of all, the research lasted for forty five days which is not an enough period of time to assess all aspects of students' knowledge of foreign language vocabulary. Second, the population of the study is small. Only forty students might not sufficiently represent the majority of students at this level. Third, the instruments used in this study could be more diversified to investigate the relative effectiveness of different kinds of mobile dictionaries separately and comparatively (e.g. monolingual vs. bilingual dictionary). Moreover, a more comprehensive questionnaire could be devised to reflect more precisely the learners' attitude towards the mobile dictionaries.

\section{References:}

Ally, M. (Ed.). (2009). Mobile learning transforming the delivery of Education and training. Edmonton: AU Press.

Amirian, S. M., \& Heshmatifar, Z. (2013). The impact of using electronic dictionary on vocabulary learning and retention of Iranian EFL learners. International Journal of Research studies in Educational Technology, 2(1), 35-44. http://dx.doi.org/10.5861/ijrset.2013.384

Baleghizadeh, S., \& Oladrostam, E. (2010). The effect of mobile assisted language learning (MALL) on grammatical accuracy of EFL students. MEXTESOL Journal, 34(2).

Canale, M., \& Swain, M. (1980). Theoretical bases of communicative approaches to second language teaching and testing. Applied Linguistics, 1(1), 1-47. http://dx.doi.org/10.1093/applin/1.1.1

Canny, J. (2010). Microsoft research program. Retrieved May 5, 2012 from http://research-microsoft.com/en-us/collaboration/papers/berkely.pdf

Chan, T.W., Roschelle, J., His, S., Kinshuk, Sharples, M., Brown, T., Patton, C., Cherniavsky, J., Pea, R., Norris, C., Soloway, E., Balacheff, N., Scardamelia, M., Dillenbourg, P., Looi, C.-K., Milrad, M., \& Hoppe, U. (2006) One-to-one technologyenhanced learning: an opportunity for global research collaboration. Research and Practice in Technology Enhanced Learning 1, 3-29. http://dx.doi.org/10.1142/S1793206806000032

Clarke, P., Keing, C., Lam, P., \& Mc Naught, C. (2008, June 30-July 4). Using SMSs to engage students in language learning. In E. R. Weipp \& J. Luca (Eds.), ED-MEDIA 2008 (pp. 6132-6141). Paper presented at the 20th annual World Conference on Educational Multimedia, Hypermedia \& Telecommunications, Vienna, Austria. 
Cruz-Flores, R., \& López-Morteo, G. (2008, October 6-10). “A model for collaborative learning objects based on mobile devices". Paper presented at the 9th Mexican International Conference on Computer Science, Baja.California, Mexico, pp.89-95.

Derakhshan, A. \& Khodabakhshzadeh, H. (2011). Why CALL not MALL: An in-depth review of text-message vocabulary learning. Theory and Practice in Language Studies, 1(9), 1150-1159. http://dx.doi.org/10.4304/tpls.1.9.1150-1159

Fotouhi-Ghazvinchi, F., Earnshaw, R., Robinson, D., \& Excell, P. (2009). The MOBO City: A mobile game package for technical language learning. iJIM, 3(2), 19-24.

Ghorbandordinejad, F., Aghasafi, A., Farjadnasab, A., Hardani, A. (2010, December). Mobile handheld recording devices in the general English classroom. Paper presented at the first symposium of educational technology, Oman.

Griffin, G. (2010). Mobile learning is beyond its tipping point. Retrieved June 9, 2011 from http://www.parrotscience.wordpress.com

Jarvia, P., Holford, J., \& Griffin, C. (2003). The theory and practice of Learning. London: Kogan Page.

Keegan, D. (2002). The future of learning: From eLearning to mLearning. Hagen, Germany: Fern Universitat.

Khazaei, S. \& VahidDastjerdi, H. (2011). An investigation into the impact of traditional vs. blended teaching on EFL learners' vocabulary acquisition: M-Learning in focus. International Journal of Humanities and Social Science, 1(15), 202-207.

Kim, D., \& Gilman, D. A. (2008). Effects of text, audio, and graphic aids in multimedia instruction for vocabulary learning. Educational Technology \& Society, 11(3), 114-126.

Klopfer, E., Squire, K., and Jenkins, H. (2002, August 30). Environmental Detectives: PDAs as a window into a virtual simulated world. Paper presented at IEEE International Workshop on Wireless and Mobile Technologies in Education. Vaxjo, Sweden. http://dx.doi.org/10.1109/WMTE.2002.1039227

Kukulska-Hulme, A. \& Shield, L. (2008). "An overview of mobile assisted language learning: Can mobile devices support collaborative practice in speaking and listening?" Retrieved February 14, 2011 from http://portal.acm.org/citation.cfm?id=1520087

Kukulska-Hulme, A., \& Traxler, L. (2005). Mobile learning: A handbook for educators and trainers. London: Routledge.

Lai, Y. L. (2005). Teaching vocabulary learning strategies: Awareness, Beliefs, and practices. A survey of Taiwanese EFL senior high school teachers. Unpublished masteral thesis. University of Essex, England.

Lin, Z. (2002). Discovering EFL learners' perception of prior knowledge and its role in reading comprehension. Journal of Research in Reading, 25(2), 172-190. http://dx.doi.org/10.1111/1467-9817.00167

Looi, C.-K., Seow, P., Zhang, B., So, H.-J., Chen, W., \& Wong, L.-H. (2010). Leveraging mobile technology for sustainable seamless learning: a research agenda. British Journal of Educational Technology, 42(1), 154-169. http://dx.doi.org/10.1111/j.1467-8535.2008.00912.x

McCarthy, M., McCarthy, J. \& Sandiford, H. (2005). Touchstone 3. New York: Cambridge University Press.

Miangah, T. M. \& Nezarat, A. (2012). Mobile-Assisted Language Learning. International Journal of Distributed and Parallel Systems (IJDPS), 3(1), 309-319. http://dx.doi.org/10.5121/ijdps.2012.3126

Motallebzadeh, K., Beh-Afarin, R., \& Daliry Rad, S. (2011). The effect of short sessage service on the retention of collocations among Iranian lower intermediate EFL learners. Theory and Practice in Language Studies, 1(11), 1514-1520. http://dx.doi.org/10.4304/tpls.1.11.1514-1520

Motallebzadeh, K. \& Ganjali, R. (2011). SMS: Tool for L2 vocabulary retention and reading comprehension ability. Journal of Language Teaching and Research, 2(5), 1111-1115. http://dx.doi.org/10.4304/j1tr.2.5.1111-1115

O’Malley, C., Vavoula, G., Glew, J. P., Taylor, J., Sharples, M. \& Lefrere, P. (2003). MOBIlearn WP4 Guidelines for Learning/Teaching/Tutoring in a Mobile Environment. Retrieved October 2, 2011, from http://www.mobilearn.org/download/results/ guidelines.pdf

Oxford, R. (1990). Language learning strategies: What every teacher should know. Boston: Heinle\&Heinle Publishers.

Salaberry, M. R. (2001). The use of technology for second language learning and teaching: A retrospective. 
Exploring the effect of Java mobile dictionaries on Iranian EFL students' vocabulary learning

Modern Language Journal, 85, 39-56. http://dx.doi.org/10.1111/0026-7902.00096

Schmitt, N. (1997). Vocabulary learning strategies. In Schmitt, N., \& Mc Carthy, M. (Eds.), Vocabulary, description, acquisition, and pedagogy. (pp. 199 - 2 27). Cambridge: Cambridge University Press.

Segler, T. M., Pain, H., \& Sorace, A. (2002). Second language vocabulary acquisition and learning strategies in ICALL environment. Computer Assisted Language Learning, 15(4), 409-422. http://dx.doi.org/10.1076/call.15.4.409.8272

Tai, Y., \& Ting, Y. L. (2011). Adoption of mobile technology for language learning: Teacher attitudes and challenges. JALT CALL journal, 7(1), 3-18.

Thornton, P. \& Houser, C. (2005). Using mobile phones in English education in Japan. Journal of Computer Assisted Learning, 21(3), 217-228. http://dx.doi.org/10.1111/j.1365-2729.2005.00129.x

Traxler, J. (2009). Learning in a mobile age. International Journal of Mobile and Blended Learning, 1(1), 1-12. http://dx.doi.org/10.4018/jmbl.2009010101

Wong, L. H., \& Looi, C. K. (2010). Vocabulary learning by mobile-assisted authentic content creation and social meaning-making: two case studies. Journal of Computer Assisted Learning, 26, 421-433. http://dx.doi.org/10.1111/j.1365-2729.2010.00357.x

Wilkins, D. A. (1972). Linguistics in language teaching. London: Edward Arnold.

Wong, L.-H., Chin, C.-K., Tan, C.-L., \& Liu, M. (2010). Students' personal and social meaning making in a Chinese idiom mobile learning environment. Educational Technology \& Society, 13(4), 15-26.

Zhao, Y. (2005). The future of research in technology and second language education. In Zhao, Y. (Ed.), Research in technology and second language learning: Developments and directions (pp. 445-457). Greenwich, CT: Information Age Publishing, Inc. 
Mostafa, Z. \& Zahra, A. 